\title{
Revista Brasileira de Atividade Física e Saúde: caminhando para a indexação na coleção SciELO
}

José Cazuza de Farias Júnior ${ }^{1}$, Cassiano Ricardo Rech², Airton José Rombaldi³, Matheus Pintanel Freitas ${ }^{3}$, Alcides Prazeres Filho'

A Revista Brasileira de Atividade Física e Saúde (RBAFS) completou 21 anos de existência em 2016 (seu primeiro número foi publicado em 1995) e é o periódico oficial da Sociedade Brasileira de Atividade Física e Saúde (SBAFS) desde a criação desta, em 2007. É uma publicação com periodicidade bimestral, de acesso aberto (open access), de caráter multidisciplinar, e o único da área da Educação Física, no Brasil, que tem como foco a publicação de estudos de elevado mérito científico que contribuam para avanços na área de Atividade Física e Saúde.

Atualmente, a RBAFS está indexada no LILACS (Índice de Literatura Latino-Americana e do Caribe em Ciências da Saúde) e no SIBRADID (Sistema Brasileiro de Documentação e Informação Desportiva), e classificada como B2 no QUALIS CAPES (Coordenação de Aperfeiçoamento de Pessoal de Nível Superior). Uma das prioridades da diretoria da SBAFS e do conselho editorial da RBAFS é indexá-la na SciELO (Scientific Electronic Library Online). Porém, em 2015, com base na avaliação dos consultores $a d$ hoc, a solicitação de indexação foi indeferida pelo conselho editorial da SciELO. Os principais problemas apontados foram: i) baixo percentual de artigos em inglês e de autores, editores e revisores com afiliação institucional no exterior; ii) elevada concentração de artigos de autores das regiões Sul e Sudeste do País; iii) ausência de um sistema ou serviço de controle de plágio e de gestão on-line de manuscritos); iv) inconsistências na política editorial.

É importante destacar que, quando a revista solicitou a sua indexação em 2015, os principais critérios de avaliação vigentes eram os seguintes: ter periodicidade bimestral; publicar de 60 a 72 artigos por ano, sendo $50 \%$ de originais; características de apresentação, estrutura e normalização; distribuição institucional e geográfica dos membros do corpo editorial, dos revisores ad hoc e dos autores dos artigos dos três últimos fascículos publicados ${ }^{1}$.

Em setembro de 2014, a SciELO publicou um documento com os novos critérios $^{2}$, políticas e procedimentos de avaliação de periódicos científicos para admissão e permanência de títulos em sua coleção Brasil, dentre os quais destacam-se estes: i) publicar de 60 a 80 artigos por ano, preferencialmente 80; ii) número de editores com afiliação institucional no exterior igual a 30\%; iii) pareceristas com afiliação institucional no exterior de $20 \%$ a $30 \%$; iv) número de artigos originais em

1 Universidade Federal da Paraíba - UFPB, Departamento de Educação Física, João Pessoa (PB), Brasil. Grupo de Estudos e Pesquisas em Epidemiologia da Atividade Física - GEPEAF. João Pessoa (PB), Brasil.

2 Universidade Federal de Santa Catarina - UFSC, Centro de Desportos - CDS, Florianópolis (SC), Brasil. 
inglês igual a $80 \%$; v) número de autores com afiliação institucional no exterior entre 25\% e 35\%; vi) ter índice de citações recebidas igual a índice h5 de 11 e mediana h5 igual a 15; vii) tempo médio de processamento dos manuscritos de até seis meses considerando o tempo entre as datas de submissão e de decisão final quanto à publicação, e de até doze meses considerando o tempo entre as datas de submissão e publicação do manuscrito (recomenda-se um ciclo total médio de seis meses, considerando a tendência internacional) ${ }^{2}$. Essas mudanças contribuíram para o fortalecimento do desenvolvimento da qualidade científica de sua coleção, para o aumento sustentável da sua visibilidade e do impacto dos periódicos que indexa e publica, de acordo com os padrões internacionais ${ }^{2}$.

Entretanto, o indeferimento do pedido de indexação da RBAFS, em grande parte, pode ser atribuído ao fato de que ela não foi avaliada pelos critérios vigentes no momento da submissão, mas sim pelos que foram publicados em setembro de 2014. Além de mais rigorosos, estes exigem uma ampla reformulação na política editorial, nas orientações de preparação, submissão e avaliação dos manuscritos dos periódicos científicos em relação aos que vinham sendo aplicados. Tais mudanças só poderiam se alcançadas com um planejamento e ações de longo prazo, associadas a uma política e ações de apoio aos periódicos científicos, o que não é algo muito comum no Brasil. Os editais de financiamento de edição de periódicos científicos têm adotado como um dos critérios de elegibilidade a revista estar indexada na SciELO e/ou em outras bases ainda mais rigorosas. Particularmente em relação à RBAFS, ela não ter JCR (Journal Citation Reports), não estar indexada em bases de dados de maior expressão, como PubMed, Scopus, Web of Science, dentre outras, e ser classificada como B2 no QUALIS CAPES são fatores que desestimulam os autores a enviarem artigos em inglês, sobretudo devido ao custo inerente à tradução (uma parte expressiva dos autores brasileiros paga para traduzir seus artigos para a língua inglesa). Diante desse cenário, a indexação de uma revista na área da Educação Física na SciELO passou a ser uma tarefa árdua.

Apesar dessas adversidades, o conselho editorial da RBAFS tem-se empenhado na promoção e fortalecimento de um conjunto de ações com intuito de adequar a revista aos critérios exigidos pelo Conselho Editorial da SciELO. Nesse sentido, foram realizadas várias mudanças na RBAFS, dentre as quais merecem destaque estas: i) definição de linhas editoriais nas quais a revista aceitará manuscritos (níveis, tendências, fatores correlatos e determinantes da atividade física, comportamento sedentário e da aptidão física relacionada à saúde; desenvolvimento, adaptação transcultural e validação de instrumentos para a medida da atividade física, comportamento sedentário e aptidão física relacionada à saúde e seus fatores correlatos e determinantes; consequências de indicadores de atividade física, comportamento sedentário e aptidão física relacionada à saúde sobre diferentes indicadores de saúde; efeitos de intervenções sobre a prática de atividade física, comportamento sedentário, exercício físico e aptidão física relacionada à saúde, e destes sobre diferentes indicadores de saúde; formação de recursos humanos, abordagens históricas e socioculturais em atividade física, comportamento sedentário, aptidão física relacionada à saúde, e suas inter-relações); ii) mudanças nas seções editoriais da revista, incluindo artigos sobre séries técnicas e ensaios teóricos em atividade física e saúde, editoriais, posicionamentos e carta ao editor; iii) ampliação do número de editores e revisores internacionais; iv) definição de uma prática editorial para o caso de má conduta científica; v) implementação de 
estratégias para ampliar o número de artigos publicados em inglês; vi) revisão da ficha de avaliação dos manuscritos por parte dos revisores; vii) implantação de um sistema de gestão on-line de manuscritos e de uma ferramenta de controle de plágio; viii) operação com o apoio de um sistema de gestão on-line de manuscritos, permitindo que todo o processo de submissão, avaliação e acompanhamento por parte dos autores e do corpo editorial seja mais eficiente, com a disposição de informações e estatísticas de controle do fluxo de gestão dos manuscritos.

Em decorrência dessas ações que passaram a ser implementadas em 2016, os primeiros frutos já estão sendo colhidos, e a RBAFS vem se tornando cada vez mais robusta. Considerando os dados de 2016, foram publicados 62 artigos, $44,2 \%$ estão em inglês. Os artigos publicados seguiram uma distribuição geográfica similar à que tem sido observada na produção científica da área de Atividade Física e Saúde no Brasil: 37,5\% da Sul, 35,5\% da Nordeste, 22,2\% da região Sudeste, $0,8 \%$ e $0,3 \%$ para as regiões Norte e Centro-Oeste (esse padrão está relacionado ao número de grupos de pesquisa e de programas de pós-graduação que abordam a temática da atividade física e saúde nessas respectivas regiões $\left.{ }^{3,4}\right)$; o número médio de citações de artigos da RBAFS nos manuscritos foi de 1,7, sendo que 35 dos 52 artigos publicados tinham, pelo menos, um artigo da RBAFS citado; $35 \%$ dos editores tinham afiliação institucional no exterior; o índice de citações h5 foi igual a 11 e a mediana h5 igual a $15^{5}$. Outro dado importante é que a primeira decisão quanto à recusa do artigo por falta de adequação às linhas editoriais da revista e/ ou de mérito científico foi tomada no prazo máximo de 10 dias após a data de submissão, e o tempo médio de conclusão da avaliação foi de 162 dias (nove artigos receberam a decisão final em 60 dias, 46,1\% tiveram sua avaliação concluída em até 120 dias); todos os artigos têm registro em Digital Object Identifier (DOI) e link para os textos completos.

É importante destacar que a proporção de artigos em inglês, o tempo médio da conclusão da avaliação dos artigos, periodicidade e pontualidade na publicação dos números da revista e o número médio de artigos publicados, a média de citações de artigos da revista nos manuscritos submetidos e os valores do índice h5 e a mediana h5, dentre outros indicadores, observados na RBAFS, são iguais ou superiores aos das revistas da Educação Física que já estavam indexadas na SciELO em 2015. Destaca-se que a RBAFS é um dos únicos periódicos da Educação Física que não cobra taxa de submissão e de publicação.

Sendo assim, o conselho editorial considera que o cenário da RBAFS é muito promissor. A RBAFS está caminhando a passos largos e de forma sustentável, e já atende a praticamente todos os critérios para indexação na coleção SciELO, apesar das adversidades. Em 2017, o conselho editorial solicitará uma reconsideração ao parecer que não recomendou a sua indexação, esperando que o Comitê Consultivo da SciELO considere o cenário atual e o potencial da RBAFS de figurar entre os periódicos de sua coleção.

\section{Agradecimentos}

À gestão 2016-2017 da SBAFS, pelo apoio e parceria no desenvolvimento das ações da RBAFS e, em especial, ao professor Alex Antonio Florindo, pela revisão e sugestões apresentadas para este editorial. 


\section{Referências}

1. Critérios SciELO Brasil: critérios, política e procedimentos para a admissão e a permanência de periódicos científicos na Coleção SciELO Brasil. Versão dezembro 2010. [Citado 4 Dez. 2016]. Disponível em: http://www.scielo.br/avaliacao/criterio/scielo_ brasil_pt.htm.

2. Critérios, política e procedimentos para a admissão e a permanência de periódicos científicos na Coleção SciELO Brasil. São Paulo, SP, 2014. [Citado 4 Dez. 2016]. Disponível em: http://www.scielo.br/avaliacao/20141003NovosCriterios_SciELO_Brasil.pdf.

3. Kienteka M, Stocchero CMA, Fueyo JL, Andrade RLM, Peixoto MB. Atividade física e saúde: produção científica em periódicos da Educação Física no Brasil. Rev Bras Ativ Fis e Saúde 2014; 19(4):410-12.

4. Silva BGC, Rey-Lopez JP, Hartwig FP, Barbosa-Silva TG, Bielemann RM, Coll CVN. A contribuição do Brasil para a pesquisa em atividade física e saúde no cenário internacional. Rev Bras Ativ Fis e Saúde 2014; 19(5):618-24.

5. Google Scholar Metrics. [Citado 4 Dez. 2016]. Disponível em: https://scholar.google. com.br/citations?view_op=top_venues\&hl=pt-BR. 